\title{
CASH \& CARRY STORE LOCATION SELECTION USING ANALYTIC NETWORK PROCESS: AN APPLICATION IN TURKEY
}

\author{
Tuncay Gürbüz \\ Industrial Engineering Dept. \\ Galatasaray University \\ Istanbul, Turkey \\ E-mail: tuncaygurbuz09@gmail.com \\ Hande Arık \\ Industrial Engineering Dept. \\ Bahçeşehir University \\ Istanbul, Turkey \\ E-mail: handearik88@gmail.com \\ Y. Esra Albayrak \\ Industrial Engineering Dept. \\ Galatasaray University \\ Istanbul, Turkey \\ E-mail: ealbayrak@gsu.edu.tr
}

This research has been financially supported by Galatasaray University Research Fund

\begin{abstract}
Location selection problem is one of the most crucial decision problems for cash \& carry stores. This study gives a multi-criteria model for that decision problem. A real life application is given throughout the study. Interactions among the decision criteria have been taken in consideration in order to better reflect the real life decision environment where the application of the decision model has been performed. Analytic Network Process is used in order to achieve a final decision among the three alternative locations for one of the largest cash \& carry chain in Turkey.
\end{abstract}

Keywords: Cash \& Carry, location selection, ANP. 


\section{Introduction}

Store location selection is one of the key strategic decisions for long term success for a retailer (Kuo et al. 2002). Due to development of economic and social conditions, external services market has led to the popularization out of home consumption. In the out of home consumption market, wholesale (cash \& carry - C\&C) products are purchased from manufacturer and sold to corporate and professional customer such as restaurant and cafe owners, companies, canteens, grocery stores, and hotels.

With the growth of wholesale market, corporate customers have been in need of C\&C stores for one stop shopping. In the wholesale sector, customers shop at C\&C store by using their membership card and are given a discount redundant for their bulk purchases. Choosing the location of store is the most important decision for the competitive advantage for the companies who operate $\mathrm{C} \& \mathrm{C}$ stores. Companies have to analyze and determine the relationship between criteria which have influence on the location decision in order to capture a sustained competitive advantage. The purpose of this study is to present a multi-criteria location selection model for $\mathrm{C} \& \mathrm{C}$ stores.

In this study, Analytic Network Process (ANP) will be used in order to select the location for a $\mathrm{C} \& \mathrm{C}$ store. The rest of the study is organized as follows: Section 2 will give a compact literature survey on ANP and store location selection problem. Section 3 briefly explains the selection of criteria and the interactions among them. A real life application executed in one of the biggest wholesale company in Turkey will be given in Section 4 . And the concluding remarks will be mentioned in Section 5.

\section{Literature Review}

Good location selection is a strategic advantage for a company in the wholesale sector. There are many studies about retail store location selection. A literature survey has been performed by Turhan et al. in 2013 in order to give store location selection criteria in retail context. However, the literature does not give any research about the $\mathrm{C} \& \mathrm{C}$ store location selection.

In the last decade, ANP is used for various location selection problems such as shipyard location selection (Güneri et al. 2009), solid waste facility location selection (Khadivi \& Fatemi Ghomi, 2012), oil jetty location selection (Hasanzadeh \& Danehkar, 2014) and undesirable facilities location selection (Tuzkaya et al., 2008).

\section{Proposed Decision Model}

In this study, ANP method is used to solve a multi-criteria decision problem of location selection for $\mathrm{C} \& \mathrm{C}$ stores in Turkey. Criteria such as potential customers, competition conditions and environmental conditions and their sub-criteria are determined and then used to evaluate the decision problem's alternative locations (cities), namely Balikesir (C1), Bursa (C2) and Denizli (C3).

A key strategic value driver is choosing the right criteria to prioritize the best alternative. Potential customers, competition and environmental conditions are effective on C\&C store location selection. The aim is choosing a store location with high customer potential, low competition and suitable environmental conditions.

Potential Customer (PC) criteria include sub-criteria such as number of hotels $(\mathrm{NH})$, restaurants (NR), cafes (NC), canteens (NCT) and groceries (NG). High potential customer density has critical importance in making location selection decisions. 
Competitive conditions (CC) criteria show region based number of competitors who operate $\mathrm{C} \& \mathrm{C}$ stores. Target customers of competitors are considered and the relationship between customers and competitors are determined. "Trade ability and production potential index" (TAPPI), "Accessibility index" (AI), "Economic effectiveness and boom index" (EEBI), "hard infrastructure index" (HII) and "Social capital index" (SCI) are defined as sub-criteria under the Environmental Conditions (EC) criteria. Sub-criteria values are obtained from Deloitte and URAK research that is called "Intercity Competitiveness Index".

The network of the proposed evaluation model is presented in the following figure where the interactions among different elements are also shown:

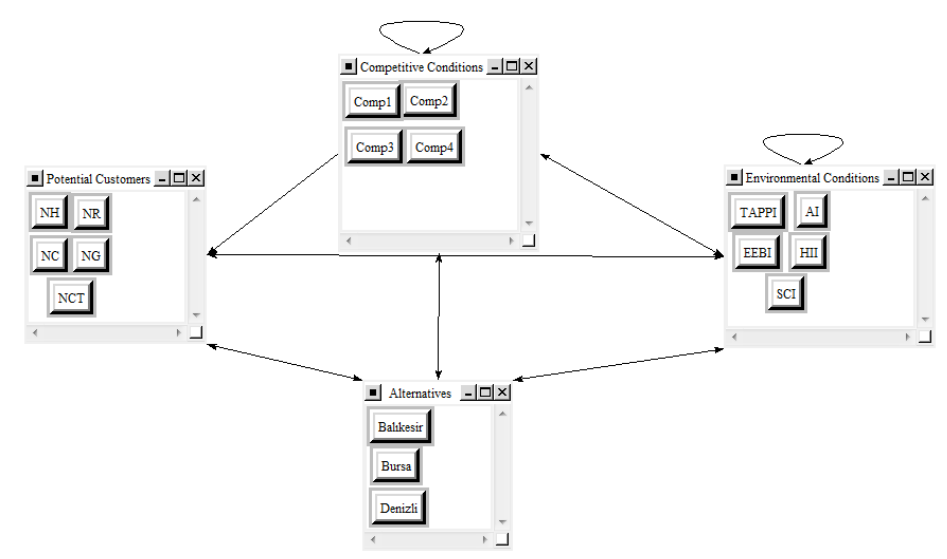

Figure 1. C\&C Store Location Selection Decision Network

Environmental Conditions Interactions: GNI per capita and the decrease in unemployment ratio increase EEBI, and because of that, variables such as used credit amount and number of companies performing external commerce increase, resulting an increase of the TAPPI criteria.

As clients, customers such as hotels, restaurants, coffee shops, canteens and grocery stores are targeted. Location selection according to the number of these type of customers is very important. On the other hand their potential buying power is different from one another therefore this affects the structure of alternative cities.

SCI defines the social atmosphere of the alternative cities. High levels of this index determine how appropriate the location would be for a $\mathrm{C} \& \mathrm{C}$ store.

The number of competitors, their potential, and their power will change the dynamics CC. In a similar way, EC will determine the shape of CC and one has to note that the CC will also modify the indices mentioned under EC. PC will determine the potential demand of the region and therefore have an important role on $\mathrm{CC}$ and the modifications on indices in EC.

\section{Numerical Application}

With respect to the previously defined interactions, pairwise comparisons of criteria and sub-criteria are performed by experts who are C\&C concept managers and the eigenvectors retrieved from comparison matrices are collected in the following supermatrix which is then normalized using the cluster matrix given in Table 2. 
IJAHP Article: Mu, Saaty/A Style Guide for Paper Proposals To Be Submitted to the International Symposium of the Analytic Hierarchy Process 2014, Washington D.C., U.S.A.

Table 1. Unweighted Supermatrix

\begin{tabular}{|c|c|c|c|c|c|c|c|c|c|c|c|c|c|c|c|c|c|}
\hline & $\mathrm{C} 1$ & $\mathrm{C} 2$ & C3 & NCT & NG & $\mathrm{NC}$ & $\mathrm{NH}$ & NR & Comp1 & Comp2 & Comp3 & Comp4 & AI & EEBI & HII & SCI & TAPPI \\
\hline $\mathrm{C} 1$ & 0,00 & 0,00 & 0,00 & 0,10 & 0,07 & 0,06 & 0,20 & 0,04 & 0,09 & 0,16 & 0,13 & 0,10 & 0,06 & 0,04 & 0,05 & 0,06 & 0,03 \\
\hline $\mathrm{C} 2$ & 0,00 & 0,00 & 0,00 & 0,07 & 0,11 & 0,12 & 0,04 & 0,14 & 0,22 & 0,16 & 0,17 & 0,15 & 0,06 & 0,05 & 0,07 & 0,06 & 0,06 \\
\hline C3 & 00 & 0,00 & 0,00 & 0,08 & 0,08 & 0,07 & 0,02 & 0,07 & 0,10 & 0,10 & 0,11 & 0,16 & 0,05 & 0,04 & 0,06 & 0,06 & 0,04 \\
\hline NCT & 0,40 & 0,29 & 0,48 & 0,00 & 0,00 & 0,00 & 0,00 & 0,00 & 0,01 & 0,08 & 0,08 & 0,08 & 0,04 & 0,02 & 0,03 & 0,02 & 0,02 \\
\hline NG & 0,16 & 0,26 & 0,23 & 0,00 & 0,00 & 0,00 & 0,00 & 0,00 & 0,01 & 0,12 & 0,12 & 0,12 & 0,04 & 0,02 & 0,03 & 0,02 & 0,02 \\
\hline $\mathrm{NC}$ & 0,01 & 0,02 & 0,01 & 0,00 & 0,00 & 0,00 & 0,00 & 0,00 & 0,05 & 0,01 & 0,01 & 0,01 & 0,09 & 0,05 & 0,10 & 0,12 & 0,05 \\
\hline $\mathrm{NH}$ & 0,07 & 0,02 & 0,01 & 0,00 & 0,00 & 0,00 & 0,00 & 0,00 & 0,11 & 0,01 & 0,01 & 0,01 & 0,13 & 0,13 & 0,16 & 0,10 & 0,13 \\
\hline NR & 0,14 & 0,18 & 0,04 & 0,00 & 0,00 & 0,00 & 0,00 & 0,00 & 0,07 & 0,01 & 0,01 & 0,01 & 0,13 & 0,09 & 0,11 & 0,17 & 0,09 \\
\hline Comp1 & 0,01 & 0,02 & 0,00 & 0,00 & 0,00 & 0,00 & 0,00 & 0,00 & 0,07 & 0,01 & 0,01 & 0,01 & 0,00 & 0,18 & 0,00 & 0,00 & 0,18 \\
\hline Comp2 & 0,00 & 0,01 & 0,03 & 0,00 & 0,00 & 0,00 & 0,00 & 0,00 & 0,01 & 0,04 & 0,02 & 0,02 & 0,00 & 0,04 & 0,00 & 0,00 & 0,04 \\
\hline Comp3 & 0,04 & 0,04 & 0,03 & 0,00 & 0,00 & 0,00 & 0,00 & 0,00 & 0,01 & 0,03 & 0,04 & 0,05 & 0,00 & 0,04 & 0,00 & 0,00 & 0,04 \\
\hline Comp4 & 0,01 & 0,00 & 0,01 & 0,00 & 0,00 & 0,00 & 0,00 & 0,00 & 0,01 & 0,03 & 0,02 & 0,02 & 0,00 & 0,04 & 0,00 & 0,00 & 0,04 \\
\hline AI & 0,04 & 0,03 & 0,03 & 0,08 & 0,08 & 0,10 & 0,10 & 0,08 & 0,03 & 0,03 & 0,03 & 0,03 & 0,04 & 0,04 & 0,05 & 0,05 & 0,04 \\
\hline EEBI & 0,03 & 0,04 & 0,03 & 0,24 & 0,27 & 0,16 & 0,24 & 0,15 & 0,07 & 0,08 & 0,08 & 0,08 & 0,07 & 0,06 & 0,08 & 0,10 & 0,06 \\
\hline HII & 0,04 & 0,04 & 0,04 & 0,06 & 0,08 & 0,16 & 0,20 & 0,14 & 0,03 & 0,03 & 0,03 & 0,03 & 0,10 & 0,06 & 0,09 & 0,05 & 0,06 \\
\hline SCI & 0,04 & 0,04 & 0,04 & 0,11 & 0,15 & 0,26 & 0,03 & 0,30 & 0,03 & 0,03 & 0,03 & 0,03 & 0,10 & 0,06 & 0,09 & 0,10 & 0,06 \\
\hline TAPPI & 0,01 & 0,01 & 0,01 & 0,26 & 0,17 & 0,08 & 0,17 & 0,08 & 0,07 & 0,06 & 0,06 & 0,06 & 0,09 & 0,06 & 0,09 & 0,10 & 0,06 \\
\hline
\end{tabular}

Table 2. Cluster Matrix

\begin{tabular}{l|cccc} 
& ALT & PC & CC & EC \\
\hline ALT & 0 & 0.25 & 0.413 & 0.128 \\
PC & 0.764 & 0 & 0.244 & 0.312 \\
CC & 0.070 & 0 & 0.099 & 0.280 \\
EC & 0.166 & 0.75 & 0.244 & 0.280 \\
\hline
\end{tabular}

Finally the limit matrix gives us the following results:

Table 3. Limit Spermatrix Results

\begin{tabular}{|cccccccccc|}
\hline C1 & C2 & C3 & NCT & NG & NC & NH & NR & \\
\hline 0,06 & 0,07 & 0,05 & 0,08 & 0,05 & 0,04 & 0,07 & 0,07 & \\
\hline Comp1 & Comp2 & Comp3 & Comp4 & AI & EEBI & HII & SCI & TAPPI \\
\hline 0,04 & 0,01 & 0,02 & 0,01 & 0,05 & 0,11 & 0,08 & 0,10 & 0,09 \\
\hline
\end{tabular}

\section{Limitations}

In this study, legal arrangements and political dynamics of the country have been ignored. However, the applicability of this study to real life would be more appropriate with the integration of these variables into the study.

\section{Conclusions}

In this study, criteria that determine the C\&C store location have been investigated, weighted and used in order to choose an appropriate city for a $\mathrm{C} \& \mathrm{C}$ store in Turkey.

Criteria of the model have been determined using expert ideas as well as the alternative cities which have high customer potential, low number of competitors and appropriate environmental conditions.

Accessibility of the store, SCI and number of hotels are determined as the three most important criteria. The best alternative city has been determined as Bursa whereas the worst alternative location would be Denizli. However, Bursa and Balikesir $\left(1^{\text {st }}\right.$ and $2^{\text {nd }}$ place alternatives $)$ are quite close to each other. That is why it is advised to make a new comparison using the candidate districts of these two cities and then make a final decision (district base decision making). 
IJAHP Article: Mu, Saaty/A Style Guide for Paper Proposals To Be Submitted to the International Symposium of the Analytic Hierarchy Process 2014, Washington D.C., U.S.A.

\section{Key References}

Kuo, R.J., Chi, S.C. \& Kao, S.S., (2002). A decision support system for selecting convenience store location through integration of fuzzy AHP and artificial neural network. Computers in Industry, 47, 199-214.

Turhan., G., Akalın, M., Zehir., C., (2013), Literature review on selection criteria of store location based on performance measures. Procedia - Social and Behavioral Sciences, 99, 391-402.

Güneri, A.F., Cengiz, M., Şeker, S., (2009), A fuzzy ANP approach to shipyard location selection problem. Expert Systems with Applications, 36(4), 7992-7999.

Khadivi, M.R., Fatemi Ghomi, S.M.T., (2012), Solid waste facilities location using of analytical network process and data envelopment analysis approaches. Waste Management, 32(6), 1258-1265.

Hasanzadeh, M., Danehkar, A., (2014), Environmental site selection for oil jetty using the analytical network process method case study: Boushehr, Iran. Ocean Engineering, $77,55-60$.

Tuzkaya, G., Önüt, S., Tuzkaya, U.R., Gülsün, B., (2008), An analytic network process approach for locating undesirable facilities: An example from Istanbul, Turkey. Journal of Environmental Management, 88(4), 970-983. 